\title{
Diagnostic Accuracy of Computed Tomogram in the Evaluation of a Neck Mass
}

\author{
Shrestha $M K^{1}$, Ghartimagar $D^{2}$, Ghosh $A^{2}$ \\ 'Department of Radiodiagnosis, ${ }^{2}$ Department of Pathology, Manipal Teaching Hospital, Phulbari
}

\section{ABSTRACT}

Objective: The concept of dividing extracranial head and neck into different spaces is a notion that dates back to the 1800s. Various studies have led to detailed description of the soft tissue spaces that are contained within the fascial layers. This study was carried out to determine the accuracy of computed tomogram (CT) in differentiating malignant from benign lesions in the neck, to study the spatial distribution of different types of histological groups in the neck and the prevalence of malignant versus benign diseases involving the neck.

Methods: This was a hospital-based, prospective study conducted in the department of Radiodiagnosis, Kasturba Medical college, Mangalore, from 2005-2008. A hundred consecutive patients referred for CT scan examination presenting with complaints related to involvement of neck spaces or presence of palpable neck masses were enrolled in this study. The details of all the cases regarding their radiological findings and histopathology were reviewed.

Results: Of the 100 patients studied, $53 \%$ had malignant lesions, out of which $43 \%$ were squamous cell carcinoma and $4 \%$ were metastatic lymph nodal involvement. Twenty percent of the lesions were of an infective origin while $23 \%$ were benign and congenital cystic lesions.

Conclusion: CT scan as an imaging modality has the ability to evaluate the malignant and benign tumors of the neck. Considering histopathology as the gold standard, the sensitivity of CT in detecting malignant/benign lesions was $96.5 \%$ with a specificity of $100 \%$. The positive predictive value was $100 \%$ and the negative predictive value $95.2 \%$.

Keywords: CT scan, neck mass, neck spaces

\section{INTRODUCTION}

Evaluating a palpable mass in the head and neck region and staging a known mucosal or sinonasal lesion are the primary role of the imaging of head and neck. Imaging defines the necessity of further work-up and the surgical approach for the treatment.

With the advent of the computed tomogram, it is now possible for the radiologists to visualize the complex anatomy and pathology of the neck region. In the late 1980 s and early 1990 s, the "space concept" was reintroduced and popularized as a method of helping radiologists to grasp the complexity of this region. ${ }^{1,2,3}$ By knowing the spaces and their contents, one can generate an anatomically-based differential diagnosis of the masses found in these spaces. ${ }^{4}$

\author{
Correspondence: \\ Dr. Manish Kiran Shrestha \\ Department of Radiodiagnosis, \\ Manipal teaching hospital, Phulbari, Pokhara, Nepal \\ Mobile No: 9841308859,9726143008
}


Shrestha et. al. CT evaluation of neck mass.

Benign and malignant tumors arising from the soft tissues of the neck are rare but they represent an important class of head and neck neoplasms. Noninvasive imaging is an important part of the diagnostic evaluation and treatment planning for these tumors. Computed tomograms (CT) provide excellent differentiation of fat from other tissues and are clearly superior to magnetic resonance imaging (MRI) for evaluation of bone and calcifications. Furthermore, compared to MRI, CT is less prone to motion artifacts, has better temporal resolution, and thus has better compliance with claustrophobic patients and can also be performed on patients having MR incompatible devices. Intravenous contrast with CT provides a more precise evaluation of the vascular structures while MRI is to a greater degree suitable for the evaluation of the soft tissue and neck spaces.

\section{METHODS}

This was a hospital-based, prospective study conducted at the Department of Radiodiagnosis, Kasturba Medical college, Mangalore, from 2005 - 2008. The study included all patients who underwent $\mathrm{CT}$ examinations of the neck for evaluation of neck lesions/palpable neck mass during the same period. All cases were reviewed and the relevant clinical data were collated. CT was performed with WIPRO GE Prospeed Helical CT scanners. Helical and $7 \mathrm{~mm}$ plain axial contiguous images were obtained, and in the region of interest, $5 \mathrm{~mm}$ sections were taken. Five $\mathrm{mm}$ contiguous axial sections were obtained after intravenous injection of a non-ionic contrast with the plain similar to that of the plain scans.

The CT criteria used to differentiate benign lesions were the presence of well-defined margins, a smooth wall, a density less than that of muscle, coarse globular calcification with a maintained fat plane and showing homogenous enhancement on post-contrast studies. Masses reported as malignant lesions on CT showed an - ill defined margin, a density equal to or more than that of muscle, presence of necrosis, obliteration of fat plane, heterogenous or no enhancement and infiltration into surrounding tissue and bones.

Inflammatory lesions were characterized by the presence of ill-defined margin, a density less than that of muscle, air pockets, necrosis, and a perilesion dirty fat plane with a heterogenous, peripheral thick rim of enhancement.

The patients with a neck mass also underwent biopsy and the specimens were sent for hisptopathological examination. The histopathological diagnosis were also correlated with the $\mathrm{CT}$ findings.
The details of the radiological and histopathology findings of all the cases were reviewed and analyzed using SPSS 12 software.

\section{RESULTS}

The majority of the patients were male accounting for $66 \%$ of the cases, and $34 \%$ were female. The patients' age ranged from 5 to 74 years. The diagnosis of the various neck lesions according to the age distribution is represented in Table 1 . The majority of the patients were in the age group of $51-60$ years $(n=28)$ followed by 41 - 50 years and 61 - 70 years age group $(n=19)$. The predominant lesion in the age group above 31 years of age was squamous cell carcinoma (SCC) followed by abscess. Among all malignant lesions, $29 \%$ cases were noted in the 41 - 60 years age group, while the benign lesions were distributed evenly among all age groups.

Of the lesions involving the suprahyoid neck spaces the maximum number of lesions were recorded in the pharyngeal mucosal space $(n=21)$ followed by those in the pre-styloid parapharyngeal space. In two cases the abscess was visualized to be involving the posterior cervical space. In the infrahyoid neck, the predominant lesions $(n=46)$ were observed in the visceral space of which 29 cases were contained within the supra-glottic space of the larynx. A cystic hygroma and a prevertebral abscess were detected in a five-year-old-male and female respectively. A papillary carcinoma thyroid was diagnosed in a 74- year males and an invasive moderately-differentiated supraglottic squamous cell carcinoma (SCC) was diagnosed in another 74-year male.

In the suprahyoid neck space, most of the lesions were encountered in the pharyngeal mucosal space $(\mathrm{n}=$ 21) of which $81 \%(n=17)$ was a SCC. In the prestyloid parapharyngeal space (PPS) (n = 19), 37.5 $\%$ were SCC while $27.4 \%$ were congenital cystic lesions. Within the post-styloid PPS ( $n=5), 40 \%$ were abscesses while the rest of the cases comprised of EICA pseudoaneurysm, ancient schwanomma and hemangioma.

Confined within the masticator space ( $\mathrm{n}=10)$ were malignant lesions (80 \%) such as SCC (30\%), mucoepidermoid and intra-alveolar epidermoid carcinoma $50 \%$, and abscess $20 \%$. Pleomorphic adenoma (33.4 $\%)$ was predominant in the parotid space $(\mathrm{n}=9)$ followed by abscess (22.2 \%) and mucoepidermoid and adenocarcinoma of the parotids $(22.2 \%)$. Moderately and well differentiated SCC accounted for $89 \%$ ( $n=$ 9) of cases in the buccal space. $56 \%, 67 \%$ and $80 \%$ cases constituted of abscess within the submandibular, sublingual and perivertebral spaces respectively. 
Limited to the infra-hyoid neck space, 40 cases were confined to the visceral space - larynx, comprising of $\operatorname{SCC}(67.5 \%)$, congenital cystic lesion (13.5\%) and inflammatory lesions (16.2\%). In the visceral space - thyroid ( $\mathrm{n}=9$ ), multinodular/colloid goiter (55.6\%) and thyroid carcinomas were recognized. Again, the prevailing lesion in the carotid, prevertebral, anterior and posterior cervical spaces was an abscess accounting for $40 \%, 66 \%$ and $100 \%$ of cases respectively. All the cases detected in the oral cavity/ tongue $(n=3)$ were malignant.

Table 1. Diagnosis of various neck lesions according to age distribution.

\begin{tabular}{lccccccc}
\hline Pathological / CT Diagnosis & \multicolumn{8}{c}{ Age in Years } \\
& $0-20$ & $21-30$ & $31-40$ & $41-50$ & $51-60$ & $61-70$ & $71-80$ \\
\hline Benign lesions & 1 & 4 & 2 & 3 & 2 & 3 & 1 \\
Benign congenital lesions & 2 & 2 & & 2 & 1 & 4 & 2 \\
Inflammatory lesions & 5 & 4 & 1 & 2 & 1 & 14 & 9 \\
Malignant lesions & & 2 & 6 & 13 & 14 & 14 \\
\hline
\end{tabular}

The lesions were differentiated as malignant, benign or inflammatory according to the CT characteristics, as displayed in Tables 2 and 3.

Table 2. Characteristics of lesion according to contrast enhancement patterns.

\begin{tabular}{lccccc} 
& Intense & Homogenous & Heterogenous & Peripheral & None \\
\hline Malignant lesions & - & - & 29 & 3 & 23 \\
Benign lesions & 1 & - & 6 & 2 & 9 \\
\hline Metastatic node & - & - & 2 & 3 & 5 \\
Infections / Abscess & - & - & 5 & 3 & 5
\end{tabular}

\section{Table 3. CT features of different lesions}

\begin{tabular}{|c|c|c|c|c|}
\hline \multirow{2}{*}{\multicolumn{2}{|c|}{ Presence of necrosis }} & Benign & Malignant & Inflammatory \\
\hline & & 7 & 12 & 12 \\
\hline \multicolumn{2}{|l|}{ Air pocket } & 1 & 1 & 1 \\
\hline \multicolumn{2}{|l|}{ Calcification } & 2 & 1 & - \\
\hline \multicolumn{2}{|l|}{ Vascular involvement } & 9 & 7 & - \\
\hline \multicolumn{2}{|l|}{ Bone involvement } & - & 10 & - \\
\hline \multirow[t]{3}{*}{ Fat plane obliteration } & Mild & 7 & 8 & 10 \\
\hline & Moderate & 1 & 31 & 4 \\
\hline & Severe & 1 & 11 & - \\
\hline \multirow[t]{2}{*}{ Margins } & III defined & 5 & 52 & 14 \\
\hline & Well defined & 11 & 2 & - \\
\hline \multirow[t]{2}{*}{$\begin{array}{l}\text { Density of lesions (as } \\
\text { compared to muscles) }\end{array}$} & Less dense & 13 & 2 & 9 \\
\hline & More dense & 1 & 1 & - \\
\hline \multicolumn{2}{|c|}{$\begin{array}{l}\text { An abscess appears as an ill defined, hypodense lesion } \\
\text { showing thick peripheral rim enhancement with mild } \\
\text { perilesional fat stranding (Figure 1). Benign lesions also } \\
\text { present as a hypodense, well-defined lesion showing } \\
\text { heterogenous post-contrast enhancement (Figure 2). }\end{array}$} & \multicolumn{3}{|c|}{$\begin{array}{l}\text { While the majority of malignant lesions tend to be } \\
\text { isodense showing no or heterogenous enhancement with } \\
\text { areas of necrosis within and surrounding fat infiltration } \\
\text { (Figure } 3 \text { ). Bony/laryngeal cartilage infiltration were } \\
\text { seen in } 11 \text { cases: } 3 \text { cases of well-differentiated SCC, } 6 \\
\text { cases of moderately-differentiated SCC, a case each of }\end{array}$} \\
\hline
\end{tabular}


intra-alveolar epidermoid carcinoma and post- radiation chondronecrosis.

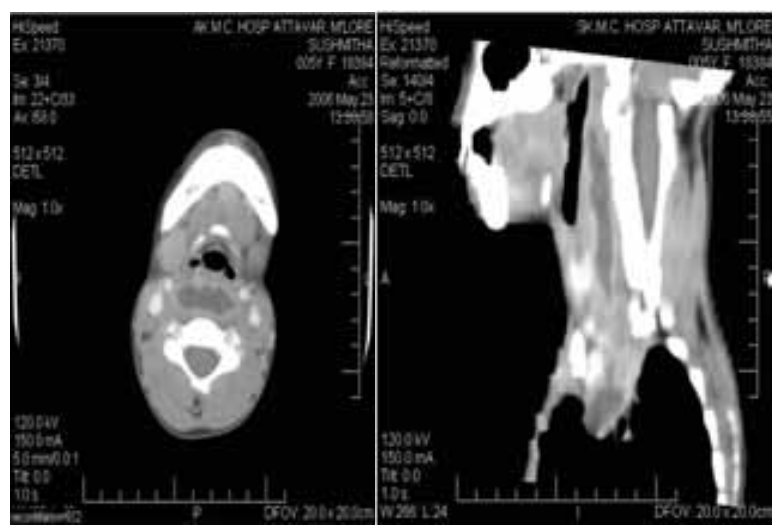

Figure 1. Prevertebral abscess extending from the level of oropharynx upto the mediastinum inferiorly

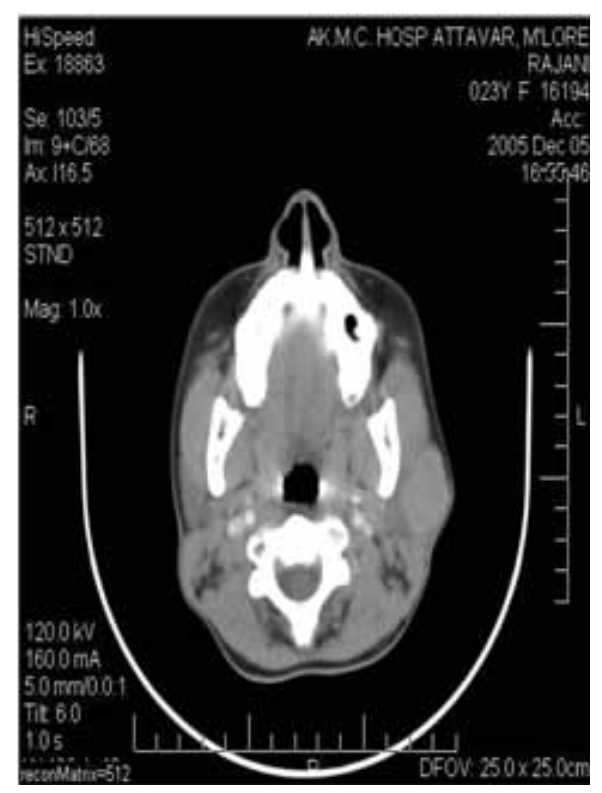

Figure 2. Pleomorphic adenoma appearing as enhancing heterogenous mass lesion in the superficial lobe of the left parotid gland



Figure 3. Right pyriform fossa keratinizing SCC extending to the aeryepiglottic fold with invasion of the thyroid cartilage

Ipsilateral nodal involvement was observed in the majority of the malignant lesions. The majority of the nodes involved were distributed in the vicinity of the lymph nodal drainage site of the lesions involving specific spaces of the neck. Necrosis and postcontrast enhancement were present in malignant nodes as compared to benign lesions. Metastatic nodal calcification was noted in a single case from papillary carcinoma of thyroid.

Fifty five lesions were diagnosed on CT as malignant. Histopathology examinations of all those lesions confirmed malignancy. Of the 42 cases identified as benign, 40 turned out to be benign while two were malignant lesions on histopathology. Of these two lesions, one was a papillary carcinoma of the thyroid, while the other one was a adenocarcinoma of the parotid gland.

The diagnoses of CT have been compared with the histopathology diagnoses in Table 4 . The sensitivity of CT in detecting malignant/benign lesions was $96.5 \%$ with a specificity of $100 \%$, positive predictive value of $100 \%$ and a negative predictive value of $95.2 \%$ (Table 4). 
Table 4. CT and Pathological Correlation of Benign Vs Malignant Lesions



Sensitivity $=96.5 \%$, Specificity $=100 \%$, Positive predictive value $=100 \%$, Negative predictive value $=95.2 \%$

\section{DISCUSSION}

The most common lesion occurring in the parapharyngeal space in this study was squamous cell carcinoma and abscess accounting for $29.1 \%$ of the cases each. 25 $\%$ of cases comprised of congenital cystic lesions. On $\mathrm{CT}$, malignant lesions predominantly comprised of illdefined margins (92\%), moderate to severe perilesional fat plane obliteration (76\%), necrosis (21\%), density equal to or more than that of muscle $(94 \%)$ and showing some or none heterogenous post-contrast enhancement (94\%). Cervical sympathetic chain schwanomma, extracranial internal carotid artery pseudoaneurysm, prominent right jugular vein and pleomorphic adenoma extending from parotid space accounted for $4.1 \%$ of the cases respectively. Hughes et $\mathrm{al}^{5}$ in his study of 172 patients with parapharyngeal neoplasm found pleomorphic adenoma as the commonest lesion (40\%) followed by paragangliomas $20 \%$, neurogenic tumors (14\%) and malignant salivary gland tumors(13\%). In a study done by Mostafa $\mathrm{MA}^{6}$, of all parapharyngeal space tumors, they noted that $90 \%$ of tumors were benign, most of them pleomorphic adenoma followed by neurofibroma. While $\mathrm{F}$. Bozza et $\mathrm{al}^{7}$ reported $66.6 \%$ $(\mathrm{n}=8$ ) as benign (pleomorphic adenoma of the deep lobe of the parotid gland) and 4 as malignant (33.4\%) consisting of recurrent parotid adenocarcinoma and squamous cell carcinoma metastasis from the occult primary and tonsil region SCC extending into the parapharyngeal space.

The disparity between present the study and other studies could be due to the fact that malignancy and abscesses are common in India due to the life style pattern, poor oral hygiene and lack of awareness. Also, the patients usually present late with the lesions. Another factor that could account for the high incidence of malignant lesions could be that the cases had been referred for diagnosing the extent of tumoral spread. Selection bias and sample size could partly be responsible for discrepancies between our studies. One case of schwannoma was reported in the present study, which corresponds with Som et $\mathrm{al}^{8}$ who reported that schwannomas accounted for $80 \%$ of neurogenic tumors.

The predominant lesion in the pharyngeal mucosal space was squamous cell carcinoma $(80.9 \%)$ in the current study, consistent with the findings of Neel $\mathrm{HB}$ et $\mathrm{al}{ }^{9}$ who reported squamous cell carcinoma to constitute $70 \%$ of adult nasopharyngeal malignancies. Moderately- differentiated SCC was seen in 12 cases. A single case of naropharyngeal angiofibroma was seen, which is consistent with the findings of Dahnert $\mathrm{W}^{10}$, who reported it as comprising $0.5 \%$ of all head and neck neoplasms.

Boucher $\mathrm{C}$ et $\mathrm{al}^{11}$ has reported abscesses in $96 \%$ of the cases involving the perivertebral and retropharyngeal space, which is consistent with the findings of $80 \%$ cases in the present study involving this space being abscesses. Most of the inflammatory lesions showed ill defined-margins, density less than or equal to that of muscle, intralesional necrotic areas, mild to moderate loss of fat planes (dirty fat) with heterogenous/thick peripheral rim enhancement. Of the lesions involving masticator space $30 \%$ was squamous cell carcinoma, which corresponds well with the study done by Hardin C.W, Hansberger H. R., Osborn A.G. ${ }^{12}$ who in a series of 16 patients detected 5 cases (31.2\%) of squamous cell carcinoma.

In present study, most of the benign lesions in the CT examination showed well-defined margins (68\%), density less than that of muscle, mild obliteration of the fat plane, presence of calcifications and with heterogenous enhancement (37\%). The only intensely enhancing benign lesion was sympathetic chain schwannoma. The benign tumors in the parotid space were pleomorphic adenoma ( 3 cases) consisting of $60 \%$ of benign tumors of the parotid gland. The remaining 40 $\%$ consisted of mucoepidermoid and adenocarcinoma of parotids. This partially corresponds to the study done by Peel R.Z and Gnepp D. R ${ }^{13}$, who reported 70 $\%$ - $80 \%$ tumors involving the parotid gland to be pleomorphic adenoma, $30 \%$ as mucoepidermoid and $28 \%$ adenocarcinoma. Nitin $\mathrm{M}$. et $\mathrm{al}^{14}$ in their series reported $66.6 \%$ patients had parotid tumors, $8.3 \%$ submandibular gland tumors while the rest had minor salivary gland lesions. About $66 \%$ were pleomorphic adenoma, two-thirds of which involved the parotid gland, and $33 \%$ had minor salivary gland lesions while 
$22.2 \%$ had major salivary gland lesions. Similarly, in a multicentre study of major salivary gland diseases, R. Fiorella ${ }^{15}$ et al reported benign tumors accounting for $80 \%$ of cases, the most frequent being pleomorphic adenoma (57.3\%). In the study, they reported 18.2 $\%$ of cases of mucoepidermoid carcinoma and $15.3 \%$ of adenoid-cystic carcinoma. Thus, these two studies correlate well with the findings of present study.

Among the lesions involving the submandibular space, and abscess was predominantly noted, constituting $62.5 \%$ of the cases. Two cases of squamous cell carcinoma were noted, amounting to $2 \%$ of the squamous cell carcinomas involving the space in the neck region, which correlates well with most of the literature.

Two cases of abscess were noted involving the sublingual space, while a case of alveolar epidermoid carcinoma was seen extending into the space. A case of plunging ranula was noted amounting to $1 \%$ of case involving the neck. This partly correlates to the study done by Torsiglievi AJ Jr et $\mathrm{al}^{16}$ who reported $3 \%$ of cases of ranula involving the head and neck. The lesions in the buccal space were SCC comprising of $88.8 \%$ of the lesions. These cases included lesions extending from the adjacent spaces or oral cavity. A case of pneumatosis glandulae parotids was noted extending into the buccal space.

In the present study, $5 \%$ of the total cases were colloid goiter, which corresponds to the study done by Vander $\mathrm{JB}$ et $\mathrm{al}^{17}$ who reported the incidence of colloid goiter to be $3 \%$ to $5 \%$ in the general population. Of the malignant tumors involving the thyroid gland, we came across two cases of medullary carcinoma, one case each of papillary and of anaplastic carcinoma of the thyroid, which is different from the study done by Hedinger $C$ et $\mathrm{al}^{18}$. This may be partly due to the small sample size of the present study. Furthermore, though CT gives structural information of the thyroid, its relationship to adjacent structures and helps in identifying thyroid lesion extension into the mediastinum, fine needle aspiration (FNA) of thyroid lesions has emerged as the default diagnostic test. The sensitivity and specificity levels for FNA are $93 \%$ and $96 \%$., respectively, with false positive and false negative rates of less than 4 $\% .{ }^{19}$

In a study on 2063 cases of neck mass lesions, 252 (12 $\%)$ were congenital neck masses. ${ }^{20}$ The most frequent congenital mass was thryglossal duct cyst (53 \%) followed by cyst of the branchial apparatus (22 \%). The majority of branchial arch anomalies (85\%) were of the second branchial arch. In the present study of the congenital cystic lesions involving the visceral space, three cases were of the second branchial cleft cyst, which accounts for more than $95 \%$ of branchial cleft disorders. ${ }^{21,22}$ There were two cases of cystic hygroma and one case of infected laryngocele. Further, there were five cases of abscess involving the visceral space with transspatial extension and a case of tubercular lympadenopathy was also noted. The malignant tumors involving larynx and hypopharynx were all SCC, which corresponds to study done by Becker $\mathrm{M}^{23}$, who reported over $90 \%$ of lesions in this space to be SCC.

The present study exhibits that the main differentiating features between benign and malignant lesions were well-defined margin and fat plane for benign lesions. While the chief features in determining the difference between inflammatory and malignant lesions were lower density of lesion, mild to moderate fat plane obliteration and thick peripheral rim enhancement in inflammatory lesions. However, the various differentiating CT features of benign, malignant and inflammatory lesions were consistent with those described by David $\mathrm{Y}$ and Kathleen M. ${ }^{24}$ The three cases that were not subjected to histopathology were two post operative/postradiotherapy cases of laryngeal tumor and a case of cervical spondylosis with large osteophytes impinging on the perivertebral space that presented as dysphagia.

Our study shows that CT, to a considerable extent, is precise in distinguishing malignant from benign lesions of the neck. Unfortunately, radiological features of most of the malignant tumors are non-specific and their differentiation from each other and thus reaching a definitive diagnosis is difficult. However, on CT scan image, a particular malignant tumor can be assigned to a particular neck space, thus reaching a narrow differential diagnosis pertaining to that space and the age of patient. By defining the extent of lesions and involvement of adjacent structures, СT helps in the planning of treatment and the portal for radiotherapy as well.

\section{CONCLUSIONS}

As an imaging modality, CT scan has the ability to evaluate the malignant and benign tumors of the neck with a diagnostic accuracy of $97.9 \%$ in the current study. The other advantages of CT are its availability, short examination time, its detailed imaging of bony structures and its ability to evaluate tumoral calcification. Thus, CT has a great role in the diagnostic accuracy and, in this part of the continent is essential in planning the surgical approach and predicting prognosis. 
Shrestha et al. CT evaluation of neck mass.

\section{REFERENCES}

1. Davis WL, Smoker WR, Harnsberger HR. The normal and diseased retropharyngeal and prevertebral spaces. Semin Ultrasound CT MR 1990; 520-33.

2. Harnsberger HR. Handbook of head and neck imaging. $2^{\text {nd }}$ ed. St.Louis: Mosby; 1995.

3. Smoker WR, Harnsberger HR. Differential diagnosis to the head and neck lesions based on their spaces of origin: The infrahyoid part of the neck. Am J Roentgenol. 1991; 157: 155 -9 .

4. Mukherji SK, Castillo M. A simplified approach to the spaces of suprahyoid neck. Radiol Clin North Am. 1998; 36 (5): 761 -80 .

5. Hughes KV $3^{\text {rd }}$, Olsen KD, McCaffrey TV. Parapharyngeal space neoplasms. Head Neck. 1995;17:124-30.

6. Mostafa MA. Clinical presentation and management of parapharyngeal space tumors. BangladeshJOtorhinolaryngol 2011; 17(1): 36-41.

7. Bozza F, Vigil MG, Ruscito P, Marzetti A, Marzetti F. Surgical management of parapharyngeal space tumors: results of 10year follow-up. Acta Otorhinolaryngol Ital 2009; 29(1):10-5.

8. Som PM, Sacher M, Stollman AL, Biller HF, Lawson W. Common tumors of the parapharyngeal space : refined imaging diagnosis. Radiology 1988; 169:81-5.

9. Neel HB, Slavitt DH. Nasopharyngeal cancer. In: Baily BI, editor. Head and neck surgery : Otolaryngology. Philadelphia: JB Lippincott; 1993.p.1257-60.

10. Dahnert W. Ear, nose and throat disorders. In: Radiology review manual. $4^{\text {th }}$ ed. Baltimore: Williams \& Wilkins; 1999.p.314-35.

11. Boucher C, Dorion D, Fisch C. Retropharyngeal abscesses. A clinical and radiological correlation. J otolaryngeal 1999; 28: 134-7.

12. Hardin CW, Harnsberger HR, Osborn AG. et al. Infection and tumour of the masticator space : CT evaluation. Radiology 1985; 157: 413-7.
13. Peel RZ, Gnepp DR. Disease of the salivary glands In: Barnes L, editor. Surgical pathology of the head and neck, vol. 1. New York: Marcel Dekker; 1985. p.535-52.

14. Nagarkar NM, Bansal S, Dass A, Singhal SK, Mohan H. Salivary gland tumors - Our experience. Indian Journal of Otolarngology and Head and Neck Surgery. 2004;56(1):31-4.

15. Fiorella R, Nicola VD, Fiorella ML, Spinelli DA, Coppola F, Luperto P. Major salivary gland disease. Multicentre study. Acta Otorhinolaryngol Ital. 2005; 25(3): 182-90.

16. Torsiglieri AJ Jr., Tom LWC, Ross AJ III, Wetmore RF, Handler SD, Potsic WP. Pediatric neck masses : Guideline for evaluation . Int J. Pediatr Otorhinolaryngol. 1988; 16:199210.

17. Vander JB, Gaston EA. Dawber TR. The significance nontoxic thyroid nodules. Ann Intern Med. 1968; 69:537-40.

18. Hedinger C, Williams ED, Sobin LH. WHO histological classification of thyroid tumor. A commentary on the $2^{\text {nd }}$ edition. Cancer1989;63:908-11.

19. Amrikachi M, Ramzy I, Rubenfeld S, Wheelr TM. Accuracy of fine-needle aspiration of thyoid. Arch Pathol Lab Med $2001 ; 125: 484-8$

20. Al-Khateeb TH, Al Zoubi F. Congenital neck masses: a descriptive retrospective study of 252 cases. J Oral Maxillofac Surg. 2007;65(11):2242-7.

21. Ikeda K, Kikuta N. Sasaki Y, Kusakari J, Hozawa K, Kawase T. Extracranial chondroma of the skull base arch. Otolaryngol Rhinol laryngol. 1987;243: 424-8.

22. Wang DH, Guan XL, Xiao LF, Zhang XP, Chen MG, Sun KM. Soft tissue chondroma of the parapharyngeal space : a case report. J. Laryngol Otol. 1998;112:294-5.

23. Becker M. Larynx and hypopharynx. Radiologic Clinics of North America. 1998;36( 5):891-919.

24. David MY, Kathleen M. Head and neck lesions. Radiologicpathologic correlations. Radiologic Clinics of North America 1998;36 (5): 983-1014. 